\title{
ANALISA FAKTOR YANG BERHUBUNGAN DENGAN KECEMASAN IBU DI RUANG NICU DAN NHCU DI RUMAH SAKIT PANTI RAPIH YOGYAKARTA
}

\section{Rosa Wulandari Tutik Priyani ${ }^{1,}$ Agnes Mahayanti ${ }^{2}$ Christina Ririn Widianti ${ }^{3}$}

${ }^{1}$ STIKes Panti Rapih Yogyakarta, Jl. Tantular No.401, Condongcatur, Kec.Depok, Kabupaten Slemen, Yogyakarta, email: rossawulan.rw@gmail.com ${ }^{2}$ STIKes Panti Rapih Yogyakarta, J1. Tantular No.401, Condongcatur, Kec.Depok, Kabupaten Slemen, Yogyakarta, email: agnes_mahayanti@stikespantirapih.ac.id ${ }^{3}$ STIKes Panti Rapih Yogyakarta, J1. Tantular No.401, Condongcatur, Kec.Depok, Kabupaten Slemen, Yogyakarta, email: ririn_widianti@stikespantirapih.ac.id

\begin{abstract}
ABSTRAK
Latar belakang: Hospitalisasi merupakan masuknya individu ke rumah sakit sebagai pasien untuk mendapatkan pertolongan dalam perawatan medis atau pengobatan. Perawatan secara intensif pada neonatal yang dirawat di ruang NICU atau NHCU akan menimbulkan kecemasan dan kekhawatiran bagi ibu bayi. Kecemasan merupakan rasa takut yang tidak jelas disertai dengan perasaan ketidakpastian dan perasaan tidak nyaman. Respon kecemasan merupakan hal yang paling umum yang dialami ibu ketika ada masalah kesehatan pada bayinya.
\end{abstract}

Tujuan: Tujuan penelitian ini untuk mengetahui faktor-faktor yang berhubungan dengan kecemasan ibu di Ruang NICU dan NHCU Rumah Sakit Panti Rapih Yogyakarta.

Metode: Penelitian ini menggunakan jenis kuantitatif, desain survei analitik dengan pendekatan cross sectional. Populasi pada penelitian ini adalah seluruh ibu yang mempunyai bayi yang dirawat di ruang NICU dan NHCU Rumah Sakit Panti Rapih Yogyakarta. Sample 35 responden diperoleh dengan tehnik accidental sampling. Instrumen penelitian yang digunakan yaitu kuesioner. 
Rosa Wulandari Tutik Priyani,Agnes Mahayanti,Christina Ririn Widianti Analisa Faktor Yang Berhubungan Dengan Kecemasan Ibu di Ruang Nicu dan Nhcudi di

Hasil: Ada hubungan yang signifikan antara usia ( $p$-value: 0,039$)$, pendidikan ( $p$ value: 0,028), pekerjaan (p-value: 0,010), status ekonomi ( $p$-value: 0,003), lama dirawat (p-value: 0,015), dan tidak terdapat hubungan yang signifikan antara lingkungan dengan kecemasan ibu (p-value: 0,551).

Simpulan: Faktor-faktor yang berhubungan dengan kecemasan ibu di ruang NICU dan NHCU RS Panti Rapih Yogyakarta, adalah faktor usia, pendidikan, pekerjaan, status ekonomi dan lama dirawat. Faktor yang tidak behubungan adalah lingkungan. Saran untuk perawat ruang NICU dan NHCU diharapkan untuk meningkatkan edukasi tentang kondisi bayi terhadap ibu bayi dan mengajari ibu dalam perawatan bayinya.

Kata kunci: kecemasan, NICU dan NHCU

\begin{abstract}
Background: Hospitalization is the entry of individuals into the hospital as a patient to get help in medical care or treatment. Intensive care for neonates who are treated in the NICU or NHCU will cause anxiety and worry for the baby's mother. Anxiety is a vague fear accompanied by feelings of uncertainty and discomfort. Anxiety response is the most common thing experienced by mothers when there are health problems in their babies.

Objective: The purpose of this study was to determine the factors associated with maternal anxiety in the NICU and NHCU rooms at Panti Rapih Hospital, Yogyakarta.

Methods: This study uses a quantitative, analytic survey design with a cross sectional approach. The population in this study were all mothers who had babies who were treated in the NICU and NHCU rooms at Panti Rapih Hospital, Yogyakarta. Sample of 35 respondents was obtained by accidental sampling technique. The research instrument used is a questionnaire.
\end{abstract}


Results: There was a significant relationship between age (p-value: 0.039), education (p-value: 0.028), occupation (p-value: 0.010), economic status ( $p$-value: 0.003 ), length of stay ( $\mathrm{p}$-value : 0.015), and there is no significant relationship between the environment and maternal anxiety (p-value: 0.551$)$.

Conclusion: The factors that were related to the anxiety of mothers in the NICU and NHCU rooms at Panti Rapih Hospital Yogyakarta were age, education, occupation, economic status and length of stay. The unrelated factor is the environment. Suggestions for NICU and NHCU nurses are expected to increase education about the condition of the baby to the baby's mother and teach the mother in caring for her baby.

Key words: anxiety, NICU and NHCU

\section{PENDAHULUAN}

Neonatus adalah bayi yang berusia antara nol (baru lahir) sampai usia satu bulan biasanya 28 hari(Noorbaya \& Johan, 2019). Bayi baru lahir normal adalah bayi yang lahir dengan umur kehamilan lebih dari atau sama dengan 37 minggu dengan berat lebih 2500 gram - 4000gram lahir langsung menangis, dan tidak ada cacat bawaan yang berat (Dwinda, Maita, Saputri, \& Yulviana, 2014). Keadaan dimana bayi baru lahir memiliki kondisi tertentu sehingga dokter atau perawat harus melakukan antisipasi terhadap kejadian buruk yang mungkin akan timbulini disebut dengan kondisi bayi risiko tinggi(Dwinda, dkk, 2014).

Bayi dengan risiko tinggi akan menjalani perawatan di perinatologi. Masuknya individu ke rumah sakit sebagai pasien untuk mendapatkan pertolongan dalam perawatan medis atau pengobatan disebut dengan hospitalisasi (Saputro \& Fazrin, 2017).Kasus bayi dengan risiko sedang dengan perawatan di level II NeonatusHigh Care Unit (NHCU) bayi baru lahir yang memerlukan observasi dan perawatan selama periode neonatal. Bayi risiko tinggi dengan perawatan di level IIINeonatal Intensive Care Unit (NICU) bayi baru lahir yang dalam 
Rosa Wulandari Tutik Priyani,Agnes Mahayanti,Christina Ririn Widianti Analisa Faktor Yang Berhubungan Dengan Kecemasan Ibu di Ruang Nicu dan Nhcudi di Rumah Sakit Panti Rapih Yogyakarta

keadaan kritis memerlukan observasi ketat dan tindakan intensif (Kemenkes RI No.604 tahun 2008). Perawatan secara intensif pada neonatal yang dirawat di ruang NICU atau NHCU akan membuat orang tua khususnya ibu akan menjadi cemas dan khawatir.

Kecemasan orang tua muncul ketika melihat banyaknya fasilitas medis di ruang NICU dan NHCU.Kondisi bayi yang tidak bisa dikunjungi setiap saat karena jam kunjung hanya dua kali dalam sehari itupun hanya melihat melalui kaca, hal ini juga menimbulkan kecemasan dan kekhawatiran bagi ibu bayi.Kecemasan merupakan rasa takut yang tidak jelas disertai dengan perasaan ketidakpastian, ketidakberdayaan, isolasi dan dan perasaan tidak nyaman (Stuart, 2016). Berdasarkan hasil penelitian Mutiara dan Hastuti (2016) bahwa tingkat kecemasan orang tua bayi BBLR umumnya sedang-berat.

RS Panti Rapih adalah salah satu rumah sakit swasta di Yogyakarta dan sebagai rumah sakit rujukan.Ruang NICU dan NHCURS Panti Rapih sudah mempunyai fasilitas alat-alat medis yang sangat lengkap. Pada tahun 2020 triwulan pertama Bed Occupancy
Ratio(BOR) RS Panti Rapih ruang NICU $119 \%$ dan NHCU 55,2\%. Sepuluh besar kasus yang ada di ruang tersebut adalah; bayi lahir Sectio Caesaria (SC), hyperbilirubinemia, Berat Badan Lahir Rendah (BBLR), bayi lahir dengan hyperbilirubin, icterik neonatorum, dehidrasi newborn, asphyxia, respiratory distress of newborn,bayi lahir dengan infeksi neonatal (Rekam Medis RSPR, 2019).

Dari hasil studi pendahuluan yang dilakukan pada bulan Juli 2020 dengan metode wawancara di ruang NICU dan NHCURS Panti Rapih Yogyakarta dari 8bayi yang dirawat, seluruhnya 100\%(8 ibu bayi)mengungkapkan bahwa merasa cemas dengan kondisi bayinya.Hasil dari pengamatan peneliti saat melakukan wawancara ibu bayi tampak cemas, takut, gelisah, dan sering bertanya kepada perawat mengenai kondisi bayinya.Penelitian tentang analisa faktor yang berhubungan dengan kecemasan ibu di ruang NICU dan NHCU sebelumnya belum pernah dilakukan, sehingga belum diketahui tingkat kecemasan dan factor yang berhubungan dengan kecemasan ibu di runag NICU dan NHCU. Berdasarkan uraian masalah diatas peneliti tertarik 
untuk meneliti tentang analisa faktor yang berhubungan dengan kecemasan ibu di ruang NICU danNHCUdi Rumah Sakit Panti Rapih Yogyakarta.

\section{METODOLOGI PENELITIAN}

Penelitian ini merupakan jenis penelitian kuantitatif. Penelitian ini menggunakan desain survei analitik dengan pendekatan cross sectional.Populasi pada penelitian ini adalah 44 ibu yang mempunyai bayi yang dirawat di Ruang NICU dan NHCU Rumah Sakit Panti Rapih Yogyakarta. Tehnik sampling yang digunakan dalam penelitian ini adalah accidental sampling, selama satu bulan 08 Desember 2020 - 08 Januari 2021 dengan jumlah sampel 35 responden.

\begin{tabular}{|c|c|c|}
\hline Pengumpulan data & \multirow{2}{*}{\multicolumn{2}{|c|}{$\begin{array}{l}\text { dilakukan } \\
\text { kuesioner. }\end{array}$}} \\
\hline membagikan & & \\
\hline Kuesioner menggunakan & \multicolumn{2}{|c|}{ Halminton } \\
\hline Bekerja & 23 & $65,7 \%$ \\
\hline Jumlah & 35 & $100 \%$ \\
\hline \multicolumn{3}{|l|}{ Status Ekonomi } \\
\hline \multicolumn{3}{|l|}{ Sedang } \\
\hline \multicolumn{3}{|l|}{$\mathrm{Rp} 2.500 .000)$} \\
\hline Tinggi & 12 & $34,3 \%$ \\
\hline \multicolumn{3}{|l|}{$\begin{array}{l}\text { (Rp2.500.000- } \\
\text { Rp 3.500.000) }\end{array}$} \\
\hline \multicolumn{3}{|l|}{$\operatorname{Rp} 3.500 .000)$} \\
\hline \multicolumn{3}{|l|}{ (> Rp. 3.500.000) } \\
\hline Jumlah & 35 & $100 \%$ \\
\hline \multicolumn{3}{|l|}{ Lama Bayi Dirawat } \\
\hline$<3$ hari & 9 & $25,7 \%$ \\
\hline$>3$ hari & 26 & $74,3 \%$ \\
\hline Jumlah & 35 & $100 \%$ \\
\hline
\end{tabular}

Rating Scale for Anxiety. Instrumen ini sudah dilakukan uji validitas dan relibilitas oleh Kautsar, Gustopo \& Achmadi (2015) semua item dinyatakan valid dan dinyatakan reliabel. Analisa data dilakukan analisa univariat dan analisa bivariat dengan uji statisik Fisher Excact Test dan Uji statistik KruskalWallis Test.

\section{HASIL DAN PEMBAHASAN}

Tabel. 1

Distribusi Karakteristik Responden di Rumah Sakit Panti Rapih Yogyakarta

\begin{tabular}{|c|c|c|}
\hline Variabel & $\mathrm{n}$ & Persentase \\
\hline \multicolumn{3}{|l|}{ Usia } \\
\hline $\begin{array}{l}\text { Dewasa Awal } \\
\text { (26-35 tahun) }\end{array}$ & 27 & $77,1 \%$ \\
\hline $\begin{array}{l}\text { Dewasa Akhir } \\
\text { (36-45 tahun) }\end{array}$ & 8 & $22,9 \%$ \\
\hline Jumlah & 35 & $100 \%$ \\
\hline \multicolumn{3}{|l|}{ Pendidikan } \\
\hline $\begin{array}{l}\text { Tingkat Menengah } \\
\text { (SMA) }\end{array}$ & 10 & $28,6 \%$ \\
\hline Tingkat Atas (PT) & 25 & $71,4 \%$ \\
\hline Jumlah & 35 & $100 \%$ \\
\hline
\end{tabular}

Pekerjaan

\begin{tabular}{lcc}
\hline Lingkungan RS Panti Rapih & & \\
Kondusif & 32 & $91,4 \%$ \\
Tidak Kondusif & 3 & $8,6 \%$ \\
Jumlah & 35 & $100 \%$ \\
\hline Tingkat Kecemasan & & \\
Cemas Ringan & 14 & $40 \%$ \\
Cemas Sedang & 21 & $60 \%$ \\
Jumlah & 35 & $100 \%$ \\
\hline Sumber: Data Primer, Januari 2021 \\
1. Karakteristik Responden \\
a. Usia \\
Karakteristik usia responden di \\
RS Panti Rapih Yogyakarta
\end{tabular}


Rosa Wulandari Tutik Priyani,Agnes Mahayanti,Christina Ririn Widianti Analisa Faktor Yang Berhubungan Dengan Kecemasan Ibu di Ruang Nicu dan Nhcudi di Rumah Sakit Panti Rapih Yogyakarta

hampir seluruhnya $(77,1 \%)$ adalah dewasa awal, sebagaian kecil $(22,9 \%)$ dewasa akhir. Hal ini menunjukan bahwa pada usia 26 tahun- 35 tahun wanita termasuk pada masa reproduktif wanita sudah siap dan matang untuk hamil, bahkan dari segi psikologisnya (Dewina, Putri, Sugiarto, 2018).

b. Pendidikan

Pendidikan responden sebagian besar $(71,4 \%)$ adalah tinggkat atas (PT), hampir setengahnya $(28,6 \%)$ pendidikan tingkat menengah (SMA). Pendidikan merupakan aktivitas dan usaha manusia untuk meningkatkan kepribadiannya dengan jalan membina potensipotensi pribadinya (Dewina,dkk, 2018).

\section{c. Pekerjaan}

Sebagian besar pekerjaan responden $(65,7 \%)$ adalah bekerja, dan hampir setengahnya $(34,3 \%)$ tidak bekerja. Pekerjaan adalah sekumpulan kedudukan atau posisi yang memiliki persamaan kewajiban dan tugas-tugas pokoknya (Koba, Rompas, Kalalo, 2019). d. Status Ekonomi

Sebagian besar status ekonomi responden sangat tinggi $(37,1 \%)$, $34,3 \%$ status ekonomi tinggi dan 28,6\% status ekonomi sedang. Di Yogyakarta, upah minimum provinsi disetiap kabupaten berbeda. Peneliti berasumsi bahwa responden berasal dari berbagai kabupaten dan juga provinsi, maka penghasilan setiap ibu berbeda-beda.

e. Lama dirawat

Lama perawatan sebagian besar $(74,3 \%)$ adalah bayi yang dirawat lebih dari 3 hari, dan hampir setengahnya $(25,7 \%)$ bayi yang dirawat kurang dari 3 hari. Bayi yang dirawat dengan diagnosa yang berbeda beda maka lama perawatan bayi berbeda-beda sesuai dengan kondisi bayinya (RM RSPR, 2020)

\section{f. Lingkungan}

Lingkungan Rumah Sakit Panti Rapih hampir seluruhnya $(91,4 \%)$ responden mengungkapkan kondusif dan sebagian kecil $(8,6 \%)$ responden mengungkapkan tidak kondusif. Lingkungan di Rumah Sakit Panti rapih sangat kondusif, 
di Ruang NICU dan NHCU semua alat alat medis tersedia lengkap, disaat ada bayi baru yang masuk petugas selalu memberikan orientasi tempat kepada orangtua bayi (RSPR, 2020).

\section{g. Tingkat Kecemasan}

Semua responden mengalami cemas sebagian besar(60\%) mengalami kecemasan sedang,dan hampir setengahnya (40\%) mengalami kecemasan ringan. Respon terhadap hospitalisasi paling umum yang dialami orang tua adalah kecemasan.

2. Faktor-faktor yang berhubungan dengan kecemasan ibu yang bayinya mengalami hospitalisasi di Ruang NICU dan NHCU RS Panti Rapih Yogyakarta

Tabel. 2

Hubungan Usia dengan Kecemasan Ibu di RS Panti Rapih Yogyakarta 08 Desember 2020 - 08 Januari 2021

\begin{tabular}{|c|c|c|c|c|c|}
\hline & \multicolumn{4}{|c|}{ Kecemasan } & \multirow[t]{3}{*}{$\mathrm{p}$ value } \\
\hline & \multicolumn{2}{|c|}{ Ringan } & \multicolumn{2}{|c|}{ Sedang } & \\
\hline & $\mathrm{n}$ & $\%$ & $\mathrm{n}$ & $\%$ & \\
\hline $\begin{array}{l}\text { Dewasa } \\
\text { awal (26- } \\
45 \text { tahun) }\end{array}$ & 8 & 22,86 & 19 & 54,29 & 0,039 \\
\hline $\begin{array}{l}\text { Dewasa } \\
\text { akhir (36- } \\
45 \text { tahun) }\end{array}$ & 6 & 17,14 & 2 & 5,71 & \\
\hline Jumlah & 14 & 40 & 21 & 60 & \\
\hline
\end{tabular}

Berdasarkan tabel.2, ada hubungan yang signifikan antara usia dengan kecemasan ibu. Peneliti mengungkapkan bahwa pada ibu dengan usia produktif seseorang akan mementingkan karir, dan keluarga apalagi anaknya. Hal ini sejalan dengan Mutiara dan Hastuti (2016), mengungkapkan bahwa seseorang sering kali mengalami stress pada usia dewasa awal karena pada fase usia tersebut seseorang biasanya memperhatikan pengejaran karir dan sosial. Kaplan dan Sadock yang disitasi oleh Sari (2020), juga mengungkapkan bahwa kecemasan lebih sering pada usia dewasa awal sebagaian besar kecemasan terjadi pada usia $21-45$ tahun.

Tabel. 3

Hubungan Pendidikan dengan Kecemasan Ibu Bayi di RS Panti Rapih Yogyakarta 08 Desember 2020 - 08 Januari 2021

\begin{tabular}{cccccc}
\hline & \multicolumn{4}{c}{ Kecemasan } & p value \\
\cline { 2 - 5 } & \multicolumn{2}{c}{ Ringan } & \multicolumn{3}{c}{ Sedang } \\
\cline { 2 - 5 } & $\mathrm{n}$ & $\%$ & $\mathrm{n}$ & $\%$ & \\
\hline Tingkat & 1 & 2,86 & 9 & 25,71 & 0,028 \\
menegah (PT) & & & & & \\
\cline { 1 - 4 } $\begin{array}{c}\text { Tingkat atas } \\
\text { (SMA) }\end{array}$ & 13 & 37,1 & 12 & 34,29 & \\
\hline Jumlah & 14 & 40 & 21 & 60 & \\
\hline
\end{tabular}

Sumber: Data primer Januari 2021

Berdasarkan tabel.3, ada hubungan yang signifikan antara pendidikan dengan kecemasan ibu. 
Pendidikan yang tinggi maka sesorang akan berpikir kritis untuk mencari informasi tentang penyakit yang diderita dan sehingga kecemasan seseorang dapat semakin tinggi. Hasil penelitian ini menunjukkan semakin tinggi tingkat pendidikan, maka semakin tinggi pula kecemasan ibu bayi. Penelitian ini sejalan dengan Damarwati (2012) mengungkapkan semakin tinggi tingkat pendidikan maka semakin tinggi pula tingkat kecemasan. Tingkat pendidikan ibu bayi yang tinggi, secara tidak langsung membuat ibu ingin mengetahui lebih banyak tentang penyakit yang diderita oleh bayinya, dengan demikian kecemasan ibu akan meningkat dikarenakan semakin banyaknya informasi yang diperoleh dari dokter dan perawat.

Tabel. 4

Hubungan Pekerjaan dengan

Kecemasan Ibu Bayi di RS Panti Rapih Yogyakarta 08 Desember 2020 - 08 Januari 2021

\begin{tabular}{cccccc}
\hline & \multicolumn{4}{c}{ Kecemasan } & \multirow{2}{*}{$\begin{array}{l}\text { value } \\
\end{array}$} \\
\cline { 2 - 5 } & \multicolumn{2}{c}{ Ringan } & \multicolumn{2}{c}{ Sedang } & \\
\cline { 2 - 5 } & $\mathrm{n}$ & $\%$ & $\mathrm{n}$ & $\%$ & \\
\hline $\begin{array}{c}\text { Tidak } \\
\text { bekerja }\end{array}$ & 1 & 2,86 & 11 & 31,43 & 0,010 \\
\hline Bekerja & 13 & 37,14 & 10 & 28,57 & \\
\hline Jumlah & 14 & 40 & 21 & 60 & \\
\hline
\end{tabular}

Sumber: Data Primer januari 2021

Berdasarkan tabel.4, ada hubungan yang signifikan antara pekerjaan dengan kecemasan ibu. Dari hasil penelitian didapatkan bahwa ibu yang bekerja lebih besar frekuensi mengalami kecemasan. Peneliti melihat bahwa ibu yang bekerja mengalami cemas dikarenakan ibu harus melakukan peran ganda yaitu bekerja dan merawat bayi yang sakit. Stuart \& Sundeen yang disitasi oleh Syaifina dan Hasan (2017), yang mengatakan bahwa seseorang yang memiliki peran ganda yaitu harus bekerja mencari nafkah dan menunggu bayi di Rumah Sakit akan meningkatkan aktifitas, yang akan menimbulkan kelelahan. Kelelahan sebagai konflik orang tua terhadap kepentingan bekerja dengan hospitalisasi bayinya menjadi stimulus kecemasan pada ibu bayi.

Tabel. 5

Hubungan Status Ekonomi dengan Kecemasan Ibu Bayi di RS Panti Rapih Yogyakarta 08 Desember 2020 - 08 Januari 2021

\begin{tabular}{cccc}
\hline & & $\begin{array}{c}\text { Median } \\
\text { (min- } \\
\text { max })\end{array}$ & p value \\
\hline $\begin{array}{c}\text { Kecemasan dengan } \\
\text { status ekonomi } \\
\text { sedang }\end{array}$ & 10 & 21,50 & 0.003 \\
$\begin{array}{c}\text { (Rp1.500.000 - } \\
\text { Rp2.500.000) }\end{array}$ & & & \\
\hline $\begin{array}{c}\text { Kecemasan dengan } \\
\text { status ekonomi } \\
\text { tinggi }\end{array}$ & 12 & 22,08 & \\
$\begin{array}{c}\text { (Rp2.500.000 - } \\
\text { Rp3.500.000) }\end{array}$ & & & \\
\hline $\begin{array}{c}\text { Kecemasan dengan } \\
\text { status ekonomi }\end{array}$ & & & \\
\hline
\end{tabular}


sangat tinggi (> Rp3.500.000)

Sumber: Data primer Januari

Berdasarkan tabel.5, ada hubungan yang signifikan antara status ekonomi dengan kecemasan ibu. Stuart dan Laraia (2007) yang disitasi oleh Syaifina dan Hasan (2017), mengatakan peningkatan kecemasan pada klien dapat dipengaruhi oleh keadaan ekonomi yang rendah atau tidak memadai. Bardasarkan hasil penelitian Syaifina dan Hasan (2017) yang memiliki pendapatan di bawah upah minimum provinsi mengalami cemas sedang.Ibu akan merasa takut dan cemas akan biaya yang harus dikeluarkan untuk perawatan bayi. Pembiayaan yang harus dikeluarkan membuat ibu dituntut untuk memperoleh penghasilan yang lebih besar (Apriyani, 2013). Damarwati (2012) mengungkapkan kecemasan meningkat dikarenakan semakin banyaknya informasi yang diperoleh dari dokter dan perawat, sehingga peneliti memandang kecemasan terjadi tidak hanya pada status ekonomi yang rendah tetapi juga pada status ekonomi yang tinggi dan sangat tinggi.

Tabel. 6
Hubungan Lama Dirawat dengan Kecemasan Ibu Bayi di RS Panti Rapih Yogyakarta

08 Desember 2020 - 08 Januari 2021

\begin{tabular}{|c|c|c|c|c|c|}
\hline & \multicolumn{4}{|c|}{ Kecemasan } & \multirow[t]{3}{*}{$\mathrm{p}$ value } \\
\hline & \multicolumn{2}{|c|}{ Ringan } & \multicolumn{2}{|c|}{ Sedang } & \\
\hline & $\mathrm{n}$ & $\%$ & $\mathrm{n}$ & $\%$ & \\
\hline$<3$ hari & 7 & 20 & 2 & 5,71 & 0,015 \\
\hline$>3$ hari & 7 & 20 & 19 & 54,29 & \\
\hline Jumlah & 14 & 40 & 21 & 60 & \\
\hline
\end{tabular}

hubungan yang signifikan antara lama dirawat dengan kecemasan ibu. Peneliti beranggapan ibu yang menunggu bayinya di NICU, berharap masa perawatannya tidak lama. Ibu bayi merasa bahwa bayinya yang tidak parah maka dapat segera pulang, sebaliknya bayi yang dirawat dalam jangka waktu yang lama berarti bayinya mengalami masalah serius dan mendapatkan perawatan yang intensif. Pada table.6 didapatkan data, 19 ibu cemas sedang dengan lama waktu rawat inap lebih dari 3 hari, hal ini sesuai dengan penelitian Siwi, Fatimah \& Emaliyawati (2017), semakin lama hari rawat bayi maka semakin lama waktu perpisahan antara ibu dan bayi.

Heryati (2005) yang disitasi oleh Aprianyi (2013), mengatakan menunggu anak yang sedang dirawat di Rumah Sakit menimbulkan kekhawatiran dan dan kecemasan bagi 
orang tua. Bila sesorang dirawat di Rumah Sakit yang diharapkan tentunya ada perubahan akan derajat kesehatan. Tidak ada seorang ibu yang ingin berlama -lama bayinya dirawat di Rumah Sakit. Hasil penelitian ini sejalan dengan Siwi, Fatimah \& Emaliyawati (2017), bahwa lama bayi dirawat di NICU akan menyebabkan tingkat cemas yang tinggi dan sebaliknya dikarenakan ketidakpastian terhadap kondisi bayinya. Kecemasan yang dialami oleh ibu bayi merupakan salah satu akibat dari hospitalisasi yang disebabkan karena perpisahan. Semakin lama hari rawat bayi maka semakin lama waktu perpisahan antara ibu dan bayi.

\section{Tabel. 7}

Hubungan Lingkungan dengan Kecemasan Ibu Bayi

di RS Panti Rapih Yogyakarta 08 Desember 2020 - 08 Januari 2021

\begin{tabular}{cccccc}
\hline & \multicolumn{4}{c}{ Kecemasan } & $\mathrm{p}$ \\
& \multicolumn{4}{c}{ value } \\
\cline { 2 - 5 } & \multicolumn{2}{c}{ Ringan } & \multicolumn{2}{c}{ Sedang } & \\
\cline { 2 - 5 } & $\mathrm{n}$ & $\%$ & $\mathrm{n}$ & $\%$ & \\
\hline Kondusif & 12 & 34,29 & 20 & 57,14 & 0,551 \\
\hline Tidak & 2 & 5,71 & 1 & 2,86 & \\
Kondusif & & & & & \\
\hline Jumlah & 14 & 40 & 21 & 60 & \\
\hline Sumber: Data primer Januari 2021 &
\end{tabular}

Berdasarkan tabel.7 didapatkan tidak ada hubungan yang signifikan antara lingkungan dengan kecemasan ibu. Penelitian ini berbanding terbalik dengan teori Kaplan dan Sadock yang disitasi oleh Sari (2020) bahwa pada lingkungan yang biasa ditempati akan membuat seseorang lebih nyama sehingga tidak mudah mengalami kecemasan dibandingkan bila dilingkungan yang asing. Peneliti mengungkapkan lingkungan di Rumah Sakit Panti Rapih Yogyakarta sangat kondusif, dan kecemasan ibu bayi terjadi kemungkinan dikarenakan kondisi yang lain yang mempengaruhi bayinya. Ketika bayi dirawat di ruang NICU ataupun NHCU perawat selalu mengorientasikan kondisi lingkungan sekitar dan ruangan NICU dan NHCU kepada ibu bayi, sehingga deangan penjelasan yang diberikan kepada perawat mampu mengurangi kecemasan ibu.

\section{SIMPULAN DAN SARAN Simpulan}

1. Kecemasan ibu terkait hospitalisasi bayi di ruang NICU dan NHCU Rumah Sakit Panti Rapih Yogyakarta, menunjukkan bahwasebagian besar $60 \%$ (21 responden) mengalami kecemasan sedang, dan hampir setengahnya $40 \%$ (14 responden) mengalami kecemasan ringan, 
sedangkan tidak ada responden yang mengalami kecemasan berat maupun kecemasan berat sekali.

2. Faktor yang berhubungan dengan kecemasan $\mathrm{ibu}$ yang bayinya mengalami hospitalisasi di ruang NICU dan NHCU Rumah Sakit Panti Rapih Yogyakarta, adalah faktor usia ( $p$-value 0,039$)$, pendidikan ( $p$-value 0,028), pekerjaan ( $p$-value 0,010), status ekonomi (p-value 0,003), dan lama dirawat ( $p$-value 0,015$)$.

3. Faktor yang tidak ada hubungan dengan kecemasan ibu yang bayinya mengalami hospitalisasi di ruang NICU dan NHCU Rumah Sakit Panti Rapih Yogyakarta adalah faktor lingkungan ( $p$-value 0,551$)$.

\section{Saran}

1. Bagi Rumah sakit

Diharapkan dapat meningkatkan perilaku caring dalam melakukan asuhan keperawatan sehingga membantu mengurangi kecemasan ibu yang bayinya mengalami hospitalisasi di ruang NICU dan NHCU.

2. Bagi Perawat

Berdasarkan hasil penelitian ini, diharapkan kepada perawat khususnya perawat ruang neonatus Rumah Sakit untuk meningkatkan dalam pelayanan edukasi tentang kondisi bayi, kemungkinan lama rawat inap bayi dengan memperhatikan usia, pendidikan, pekerjaan dan status ekonomi ibu bayi serta mengajarkan ibu dalam perawatan bayi.

3. Bagi peneliti lain

Bagi peneliti perlunya mengkaji lebih lanjut faktor yang paling dominan mempengaruhi tingkat kecemasan ibu terkait hospitalisasi bayi di ruang NICU dan NHCU, agar dapat meminimalkan kecemasan yang berlebihan.

\section{DAFTAR PUSTAKA}

Apriany, D. (2013). Hubungan antara hospitalisasi anak dengan tingkat kecemasan orang tua. Jurnal Keperawatan Soedirman (The Soedirman Journal of Nursing), Volume 8, No.2

Darmawati, (2012). Gambaran tingkat kecemasan orang tua bayi yang dirawat diruang nicu rsup fatmawati jakarta. Skripsi, FIK $U I$. 
Rosa Wulandari Tutik Priyani,Agnes Mahayanti,Christina Ririn Widianti Analisa Faktor Yang Berhubungan Dengan Kecemasan Ibu di Ruang Nicu dan Nhcudi di Rumah Sakit Panti Rapih Yogyakarta

Dewina, M., Putri, N, Y., Sugiarto, H. (2018) karakteristik ibu yang melahirkanbayi berat lahir rendah (bblr) di puskesmas wilayah pantura kabupaten indramayu tahun 2017. Jurnal Kesehatan Indra Husada Vol 6. No 2, Hal 60-70.

Dwinda, O., Maita, L., Saputri, E. M., \& Yulviana, R. (2014). Buku Ajar Asuhan Kebidanan Neonatus, Bayi/Balita dan Anak Prasekolah untuk Para Bidan. Yogyakarta: Deepublish.

Kementrian Kesehatan RI N0. 604/Menkes/SK/VII/2008 Tentang Pedoman Pelayanan Maternal Perinatal pada Rumah Sakit Umum Kelas B, Kelas C, dan Kelas D

Kautsar, F. Gustopo, D. \& Achmadi, F. (2015). Uji validitas dan reliabilitas hamilton anxiety rating scale terhadap kecemasan dan produktivitas pekerja visual inspection PT. Widarta Bhakti. SENATEK 588-592

Koba,E,R,.Rompas, S. Kalalo,V. (2019). Hubungan jenis pekerjaan ibu dengan pemberian asi pada bayi di puskesmas ranomuut manado. e-journal Keperawatan (e-Kp) Volume 7 Nomor 1, Hal 1-6

Mutiara, S., \& Hastuti, R. P. (2016). Faktor-faktor yang berhubungan dengan tingkat kecemasan orang tua bayi bblr di rsud hm ryacudu dan rs handayani kotabumi lampung utara. Jurnal Kesehatan Metro Sai Wawai Volume 9, No.1, 51-55.

Noorbaya, S., \& Johan, H. (2019). Panduan Belajar Asuhan Neonatus, Bayi, Balita dan Anak Prasekolah. Yogyakarta: Gosyen Publishing.

Rumah Sakit Panti Rapih. (2020).

Rekam Medis Rumah Sakit Panti Rapih. Yogyakarta.

Saputo, H \& Fazrin, I. (2017). Anak Sakit Wajib Bermain di Rumah Sakit. Ponorogo: FORIKES.

Siwi, Fatimah, \& Emaliyawati. (2017). Faktor-faktor yang berhubungan dengan kecemasan dan analisis kebutuhan orangtua yang mengalami kecemasan dengan bayi sakit kritis di nicu rsud prof.dr. Margono soekardjo purwokerto. Jurnal of Holistic Nursing Science. Vol. 4 No, 2 
Jurnal Keperawatan I CARE, Vol. 2 No. 2 Tahun 2021

Stuart, G, W. (2016). Prinsip dan

Praktik Keperawatan Kesehatan

Jiwa Stuart Buku II, Edisi

Indonesia, Singapura: Elsevier

Sari, U,S \& Abrori. (2020). Body Image.

Jakarta: PT Sahabat Alter

Indonesia

Syaifina, S \& Hasan, N. (2017).

Hubungan karakteristik dengan

tingkat kecemasan ibu bayi yang

dirawat di ruang nicu rsud dr.

zainoel abidin banda aceh.

Jurnal Ilmiah Mahasiswa

Fakultas Keperawatan. Vol 2.

No.3 